\title{
USP38 might be a new therapeutic target for glioma via regulation of cancer cell metastasis
}

\author{
Ting $\mathrm{Hu}^{1^{*}}$, Ke-Ni Wang ${ }^{2^{*}}$, Hai-Rui LingHu${ }^{1}$ \\ ${ }^{1}$ Department of Neurosurgery, Beijing Chaoyang Integrative Medicine Emergency Medical Center, Beijing, China, ${ }^{2}$ Department of \\ Cardiology, Characteristic Medical Centre of PAP, He Dong District, Tianjin, China \\ *These authors contributed equally to this work and share first authorship.
}

\begin{abstract}
Introduction: Gliomas are the most seen tumours in adults in the central nervous system, and high grade of gliomas cause the worse prognose of patients with a shorter survival period. Ubiquitin-specific protease 38 (USP38) has been regarded as the negative regulator of type I interferon signalling; it regulates the ubiquitination process of TANK binding kinase 1 (TBK1). Further study revealed that USP38 also stabilizes the protein lysine-specific histone demethylase 1A (LSD1) via cleaving the ubiquitin chain. However, the effect of USP38 in colorectal cancer was not fully understood.

Material and methods: USP38 overexpression and knockdown vector were constructed using the molecular clone method. The viability rate of U-87MG and U-138MG cells were detected using the Cell Counting Kit-8 (CCK-8) method. The expression and secretion of metastasis-related molecules were detected using the qPCR and ELISA method. The expression of metastasis-related molecules and JAK2/STAT3 signalling pathway was detected using western blotting analysis.

Results: In this study, we firstly constructed a USP38 overexpression and inhibition model in 2 cell lines and found that overexpression of USP38 inhibits the viability rate and migration ability of glioma cells. We further noticed that elevated expression of USP38 reduced the expression and secretion of cell adhesion-related molecules with the elevation in expression of pro-apoptotic proteins, and these effects might be mediated by inhibition of JAK2/STAT3 signalling pathway as USP38 is the upstream regulator of STAT3 and inhibition of cellular adhesion process.

Conclusions: USP38 might be a new therapeutic target for glioma.
\end{abstract}

Key words: glioma, USP38, vemurafenib, MMPs, LAMPS, JAK2/STAT3 signalling pathway.

\section{Introduction}

Glioma is one of the deadliest tumours, which essentially occurs in the central nervous system [31], and poor outcome is commonly observed in glioma patients due to the high invasiveness and resistance
$[22,30]$. Vemurafenib is a selective small molecule inhibitor of mutant BRAFV600E, and it has an 50\% response in patients with the BRAFV600E mutant [1]. A previous clinical trial showed that usage of this inhibitor induced apoptosis of cells, and then caused resistance and progression [27]. However, effective

\section{Communicating author}

Hai-Rui LingHu, Department of Neurosurgery, Beijing Chaoyang Integrative Medicine Emergency Medical Centre, Beijing 100022,

People's Republic of China, phone: +8613622098542, e-mail: linghuhairui001@163.com 
therapeutic for colorectal cancer (CRC) was still lacking. Deubiquitinases (DUBs) comprise a group of enzymes that can remove ubiquitin from proteins, leading to the changes in stability and activity of target proteins $[4,19]$. Members of DUBs could be divided into 5 groups, including ubiquitin-specific proteases (USPs), ovarian tumour proteases (OTUs), ubiquitin C-terminal hydrolases (UCHs), MachadoJoseph disease protein domain proteases (MJDs), and JAMM motif proteases $[3,15]$. Among them, a recent study found that depletion of USP38 in mice presents the genome aberration in comparison with wild type mice; besides, a recent study noted that ubiquitin-specific protease 38 (USP38) plays an important role in the maintenance of the integrity of genome in cells and mice, and thus reduction of USP38 expression might lead to tumourigenesis $[7,11,13]$. Thus, we thought that overexpression of USP38 might suppress the development of colon cancer. In this study, we found that overexpression of USP38 combined with vemurafenib treatment decreased the expression of MMPs and LAMPs, with the increased expression of pro-apoptotic proteins, resulting in the reduction in cellular proliferation rate and tumour metastasis ability. We further noticed that these effects might be mediated by inhibition of JAK2/STAT3 signalling pathway. Thus, we thought that overexpression of USP38 might be a therapeutic target in the treatment of glioma.

\section{Material and methods \\ Reagents}

SNX10 (SAB2107086) was purchased from Sigma. USP38 (ab72244), p53 (ab26), BAX (ab32503), JAK2 (ab108596), JAK2 (phospho Y1007 + Y1008) (ab32101), STAT3 (ab119352), STAT3 (phospho Y705) (ab76315), LAMP2 (ab13524), LAMP1 (ab25630), MMP-9 (ab38898), MMP-2 (ab97779), E-cadherin (ab76055), MMP-2 (ab254516), MMP-9 (ab253227), ICAM-1 (ab252355), and VCAM-1 (ab201278) enzyme-linked immunosorbent assay (ELISA) kits were purchased from Abcam.

\section{Cell culture and model construction}

U-87MG (HTB-14) and U-138MG (HTB-16) cell lines were purchased from ATCC. 293T (GNHu17) cells were purchased from the cell bank of the typical culture preservation committee of the Chinese Academy of Sciences. Full length of USP38 DNA was obtained using PCR method with the following primer: Forward: 5'-CGCTGCCGGTCTACGATAAA-3', Reverse: 5'-TCGATGGCACGGTTGTACTT-3'. DNA of USP38 and pcDNA3.1-blank vector were digested with BsmBI (R0580S, NEB) and BamHI (R3136S, NEB), then the USP38 overexpression vector was constructed after being linked with DNA ligase (M0202S, NEB). USP38 overexpression vector was transfected into HCT 116 cells using Lipofectamine 2000 Transfection Reagent (11668500, Thermo). Stable expressed cells were screened using $800 \mu \mathrm{g} / \mathrm{ml}$. USP38 knockdown vector was constructed according to previous description [39]. USP38 oligos were obtained using the following primer: Forward: 5'-CACCGAGGCTTGCCAATGCTACAGA-3', Reverse: 5'-AACTCCGAACGGTTACGATGTCTC-3'. Oligos and CRISRP vector were digested with $\mathrm{BsmBI}\left(37^{\circ} \mathrm{C}\right.$ for $30 \mathrm{~min}$ ). Then, digested vector and oligos were liked with Quick Ligase and transfected into 293T cells to construct a lentiviral vector. U-87MG and U-138MG cells were transfected with lentiviral vector, and stable expressed cells were screened using $2 \mu \mathrm{g} / \mathrm{ml}$ puro. Cells were cultured in H-DMEM medium with $10 \%$ fetal bovine serum (FBS) at a $37^{\circ} \mathrm{C}$ atmosphere supplied with $5 \% \mathrm{CO}_{2}$. Then, cells were divided into 4 groups: normal group (NC in U-87MG cell model, $M C$ in U-138MG cell model), vemurafenib-treated group (VT in U-87MG cell model, MT in U-138MG cell model), vemurafenib-treated combined with USP38 overexpression group (VO in U-87MG cell model, $\mathrm{MO}$ in U-138MG cell model), and vemurafenib-treated combined with USP38 inhibition group (VI in $\mathrm{U}-87 \mathrm{MG}$ cell model, MI in U-138MG cell model). In the vemurafenib treated group, cells were treated with $10 \mu \mathrm{M}$ vemurafenib for $24 \mathrm{~h}$ [23].

\section{CCK-8 assay}

Cell Counting Kit-8 (CCK-8) assay was performed according to the protocol of CCK-8 kit (CA1210, Solarbio). Briefly, cells were firstly seeded into each well of a 96-well plate at a concentration of $1 \times 10^{5}$, and then they were divided into 4 groups and treated as previously described. Then, cells were incubated with CCK-8 reagent for $4 \mathrm{~h}$, and the OD value at $450 \mathrm{~nm}$ was measured using a microplate reader (UV-3200S, MAPADA). The viability rate was measured using the following formula: viability rate $=\left(\mathrm{OD}_{\text {Experimental }}-\mathrm{OD}_{\text {Blank }}\right) /\left(\mathrm{OD}_{\text {Control }}-\mathrm{OD}_{\text {Blank }}\right)$. Each experiment was repeated 3 times independently. 


\section{Wound healing assay}

Cells were seeded into a 6-well plate at a concentration of $1 \times 10^{5}$, and then they were treated as previously described. Then a cell straight line was made using $10 \mu \mathrm{l}$ tips. After washing with sterile PBS the cells were cultured and the image was acquired after being cultured for $24 \mathrm{~h}$.

\section{RNA extraction}

RNA extraction was performed according to the protocol of total RNA extraction kits (R1200, Solarbio). Cells and tumour tissues were firstly lysed with lysis buffer, and then incubated with chloroform for $5 \mathrm{~min}$. Then, samples were transferred into an absorption tube and centrifuged at 12,000 rpm for 2 min. After washing with buffer, RNA samples were eluted with elution buffer. The concentration of RNA was measured using an ultramicro-DNA analyser (NanoGenius, MAPADA). RNA samples were stored at $-80^{\circ} \mathrm{C}$ until the following experiments were performed.

\section{Reverse transcription and real-time quantitative polymerase chain reaction}

Reverse transcription and quantitative polymerase chain reaction (qPCR) were performed according to the protocol of TaqMan One Step RT-qPCR Kit (T2210, Solarbio). Briefly, reaction mixture was made up as recommended; the primers used in this experiment are as follows: MMP-2: Forward: 5'-AACCCTTGGAGCCAATGGAGACT-3', Reverse: 5'-GGTTCTAAGGCAGCCAGCAGTG-3'; MMP-9: Forward: 5'-ATCCCTCAACATCGCAACTGT-3', Reverse: 5'-CAGCCTC TGGTAGATTATCAAGC-3';ICAM-1: Forward: 5'-CTAGCTAG CATGGCTCCCAGCAGCCCC-3', Reverse:5'-CGGATATCGGGAGGCGTGGCTTGTGTG-3'; VCAM-1: Forward: 5'-GTGA ATATGACATGCTTGAGCCAGG-3', Reverse: 5'-CATCCTTCA ACTGGGCCTTTCG-3'. The reaction was performed with the following steps: Reverse transcription at $50^{\circ} \mathrm{C}$ for $20 \mathrm{~min}$, degeneration at $95^{\circ} \mathrm{C}$ for $3 \mathrm{~min}$, and the following steps repeated for 40 cycles: degeneration at $95^{\circ} \mathrm{C}$ for $15 \mathrm{~s}$, annealing at $58^{\circ} \mathrm{C}$ for $30 \mathrm{~s}$, and extending at $72^{\circ} \mathrm{C}$ for $60 \mathrm{~s}$. Each experiment was repeated 3 times independently. Glyceraldehyde-3-phosphate dehydrogenase (GAPDH) was used as an internal control. Expression of each target gene was calculated using the $2^{-\Delta \Delta C q}$ method [17].

\section{Western blotting analysis}

Cells were grouped and treated as previously described, then cells and tumour tissues were lysed with lysis buffer, and protein samples were collected after being centrifuged at 12,000 rpm for $10 \mathrm{~min}$. Concentrations of protein samples were measured using BCA assay, and $60 \mu \mathrm{g}$ protein samples were used to perform the Western blotting analysis. Briefly, proteins were separated using 10\% SDS-PAGE electrophoresis, and proteins were transferred onto a PVDF membrane using a semi-dry transfer blotter. Membranes were blocked with $5 \%$ skimmed milk and then incubated with primary antibody at $4^{\circ} \mathrm{C}$ overnight and incubated with secondary antibody for $1 \mathrm{~h}$ at room temperature. Grey value of proteins were detected using chemiluminescent immunoassay. GAPDH was used as an internal control, and each experiment was repeated 3 times independently.

\section{ELISA}

ELISA was performed according to the protocol of ELISA kits. Briefly, cultured medium was collected and added into each well of a 96-well plate. Then, samples were incubated with antibody for $1 \mathrm{~h}$ at room temperature, and after washed with washing buffer, samples were incubated with TMB solution for $10 \mathrm{~min}$ at room temperature. After incubation with stop solution for $10 \mathrm{~min}$ at room temperature, the OD value at $450 \mathrm{~nm}$ was detected using a microplate reader (UV-3200S, MAPADA).

\section{Statistical analysis}

The data are presented as the mean \pm S.E.M. Each experiment was repeated 3 times independently. One-way ANOVA was used to analyse the differences between groups using SPSS 22.0 software. $P$-value $<0.05$ was set as a statistically significant difference.

\section{Results \\ Detection of cellular viability rate of cells}

The viability rate in the NC, VT, VO, and VI groups of U-87MG cells was $100.0 \pm 5.3,82.3 \pm 4.3,60.1$ \pm 3.2 , and $94.6 \pm 5.0$, respectively, and the viability rate of NC, VT, VO, and VI groups of U-138MG cells was $100.0 \pm 4.8,86.5 \pm 4.1,64.2 \pm 2.8$, and $94.7 \pm 4.6$, respectively (Fig. 1A). The viability rate was significantly decreased in the VT and VO groups compared 

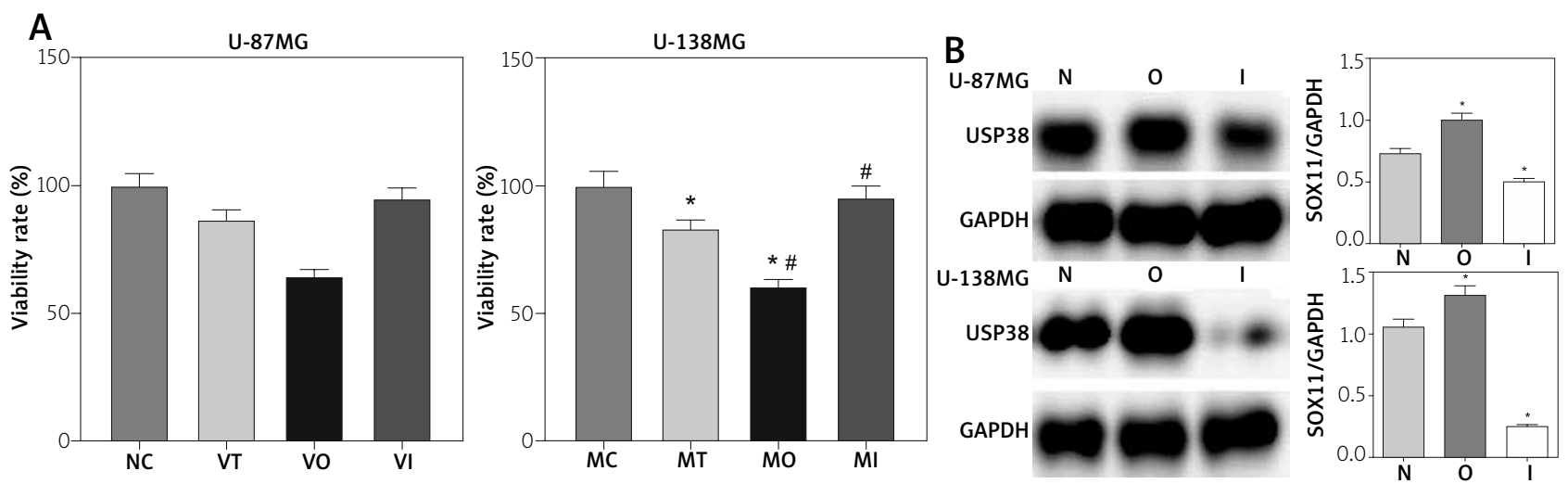

C
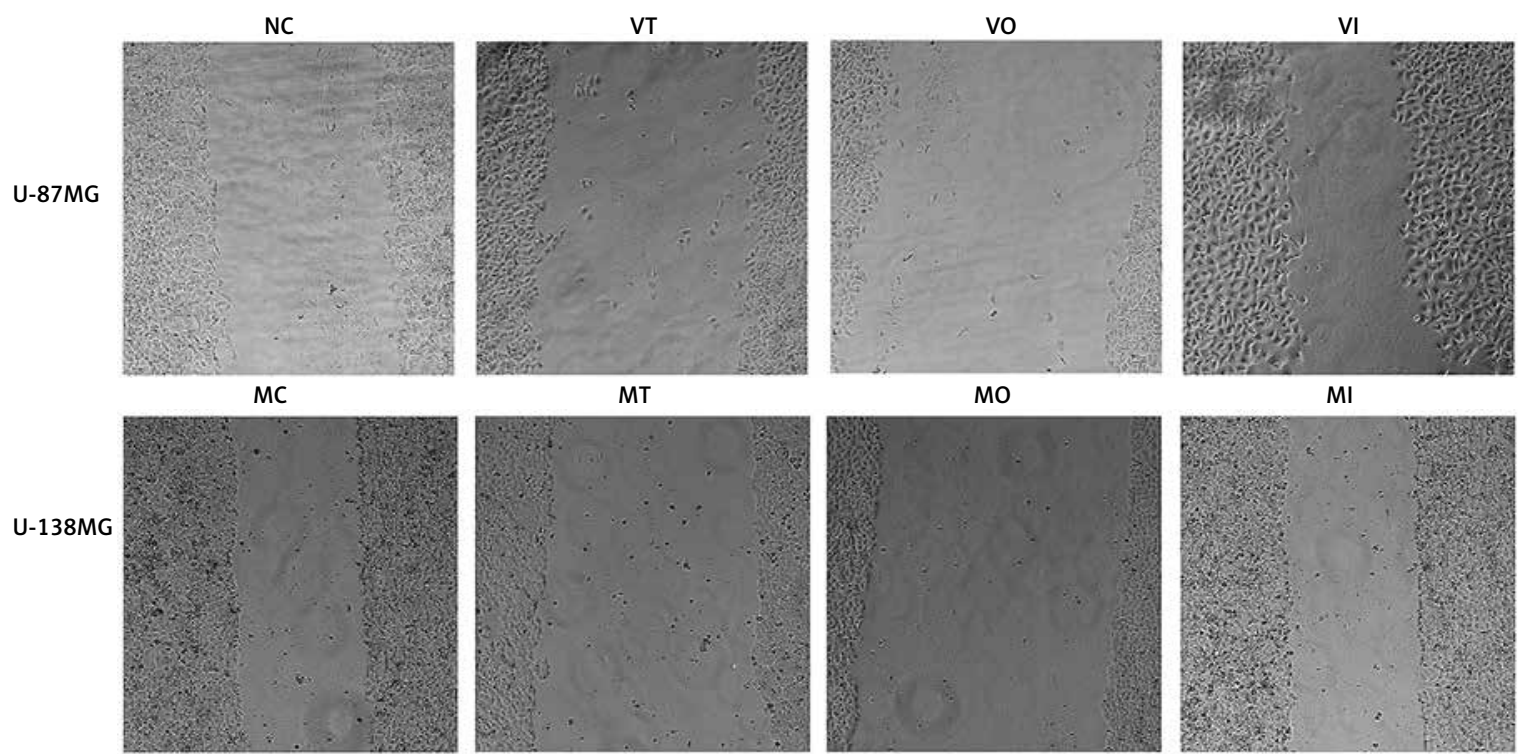

Fig. 1. Effect of vemurafenib on viability and metastasis ability of cells. A) Effect of vemurafenib on viability rate of U-87MG and U-138MG cells. B) Detection of USP38 expression in U-87MG and U-138MG cell model without treatment of vemurafenib. C) Effect of vemurafenib on metastasis ability of U-87MG and U-138MG cells. Data presented as mean \pm SD. Each experiment was repeated 3 times independently. ${ }^{*} p<0.05$ compared with control group, ${ }^{\#} p<0.05$ compared with vemurafenib treatment group.

with the NC group $(p<0.05)$, and the viability rate was significantly decreased in the VO group and significantly increased in VI group compared with the VT group ( $p<0.05$, Fig. $1 \mathrm{~A})$. The expression of USP38 in the normal, overexpression, and inhibition groups of the U-87MG and U-138MG cell models are shown in Figure 1B, and significantly increased expression of USP38 was detected in the overexpression group while significant reduction of USP38 expression was detected in the inhibition group, indicating the successful establishment of the cell model. And as shown in Figure $1 \mathrm{C}$, the distance of scratch in the NC, VT, VO, and VI groups of U-87MG cells was $1.3 \pm 0.1$,
$1.1 \pm 0.1,1.9 \pm 0.2$, and $0.7 \pm 0.1 \mathrm{~mm}$ and $0.9 \pm 0.1$, $1.3 \pm 0.1,1.7 \pm 0.1$, and $0.8 \pm 0.1 \mathrm{~mm}$, respectively. These results indicate that overexpression of USP38 enhances the effect of vemurafenib on inhibition of the proliferation and metastasis ability of cancer cells.

\section{Detection of metastasis-related actors in cell models}

As shown in Figures 2 and 3, the expression of MMP-2 in cultured medium of the NC, VT, VO, and $\mathrm{VI}$ groups of U-87MG cells was $1.7 \pm 0.1,1.3 \pm 0.1$, $0.6 \pm 0.1$, and $1.6 \pm 0.1$, respectively, and the expres- 
A
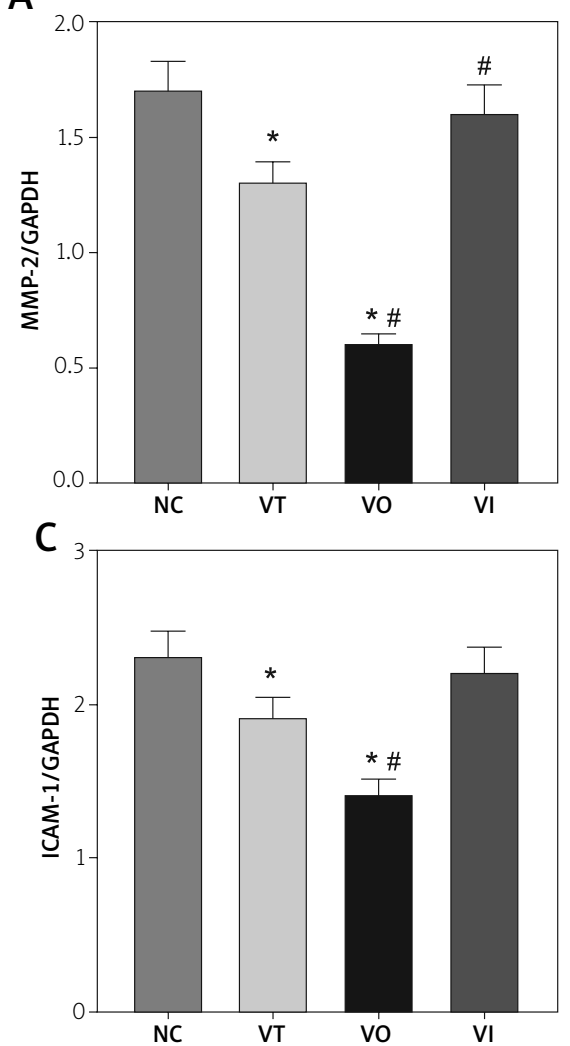

B

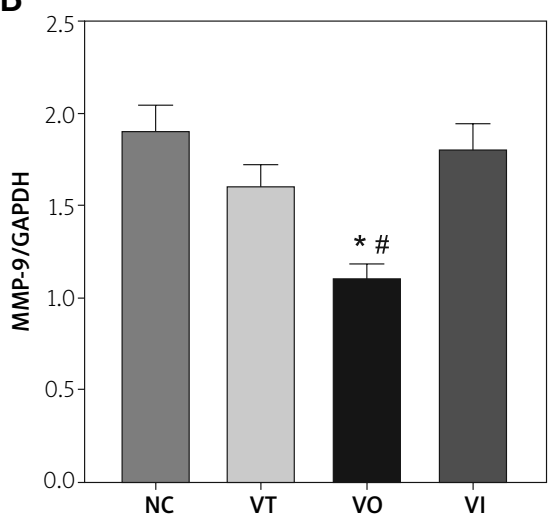

D

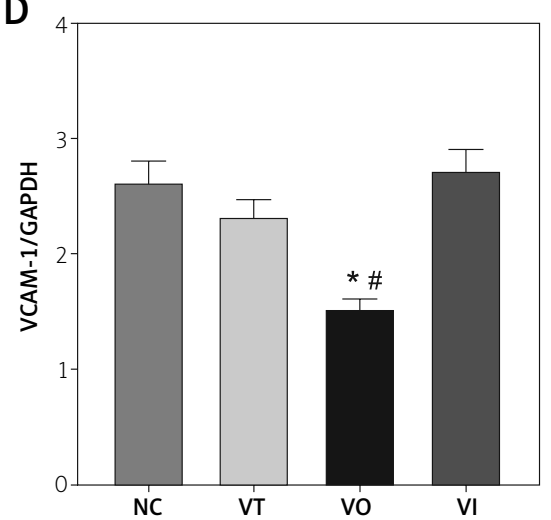

Fig. 2. Detection of metastasis-related gene expression using qPCR method in each group of U-87MG cell model under treatment of vemurafenib. A) Expression of MMP-2 in each group of cell model under treatment of vemurafenib. B) Expression of MMP-9 in each group of cell model under treatment of vemurafenib. C) Expression of ICAM-1 in each group of cell model under treatment of vemurafenib. D) Expression of VCAM-1 in each group of cell model under treatment of vemurafenib. Data presented as mean \pm SD. Each experiment was repeated 3 times independently. ${ }^{*} p<0.05$ compared with control group, ${ }^{\#} p<0.05$ compared with vemurafenib treatment group.

sion was $2.5 \pm 0.2,2.1 \pm 0.2,1.4 \pm 0.1$, and $2.6 \pm 0.2$, respectively, in culture medium of U-138MG cells in the MC, MT, MO, and MI groups. The expression of MMP-9 in each group of U-87MG cells was $1.9 \pm 0.1$, $1.6 \pm 0.1,1.1 \pm 0.1$, and $1.8 \pm 0.1$, and the expression was $2.8 \pm 0.2,2.2 \pm 0.2,1.5 \pm 0.1$, and $2.7 \pm 0.2$, respectively, in the culture medium of U-138MG cells. The expression of ICAM- 1 in each group of the $\mathrm{U}$-87MG cell model was $2.3 \pm 0.2,1.9 \pm 0.1,1.4 \pm 0.1$, and $2.2 \pm 0.2$, respectively, and the expression was $2.9 \pm 0.2,2.5 \pm 0.2,1.8 \pm 0.1$, and $2.7 \pm 0.2$, respectively, in the culture medium of U-138MG cells. The expression of VCAM- 1 in each group of the $\mathrm{U}$-87MG cell model was $2.6 \pm 0.2,2.3 \pm 0.2,1.5 \pm 0.1$, and $2.7 \pm 0.2$, respectively, and the expression was $3.2 \pm 0.2,2.7 \pm 0.2,2.1 \pm 0.2$, and $3.1 \pm 0.2$, respectively, in the culture medium of U-138MG cells.

\section{Detection of metastasis-related actors in cultured medium and serum sample}

As shown in Figures 4 and 5 , the concentration of MMP- 2 in cultured medium of the NC, VT, VO, and VI groups of $U-87 M G$ cells was $423.2 \pm 24.9,394.1 \pm 23.2$, $286.3 \pm 16.8$, and $445.7 \pm 26.2 \mathrm{pg} / \mathrm{ml}$, respectively, and the concentrations of MMP-2 were $652.1 \pm 38.4$, $588.4 \pm 34.6,496.2 \pm 29.2$, and $646.5 \pm 38.0 \mathrm{pg} / \mathrm{ml}$ in the MC, MT, MO, and MI groups of the U- $138 \mathrm{MG}$ cell model, respectively. The concentration of MMP-9 in each group of the $U-87 M G$ cell model was $472.3 \pm 27.8$, $415.2 \pm 24.4,326.1 \pm 19.2$, and $498.4 \pm 29.3 \mathrm{pg} / \mathrm{ml}$, respectively, and the concentration in each group was $772.1 \pm 45.4,695.8 \pm 40.9,604.2 \pm 35.5$, and $732.6 \pm 43.1 \mathrm{pg} / \mathrm{ml}$, respectively, in each group of the $\mathrm{U}-138 \mathrm{MG}$ cell model. The concentration of ICAM-1 

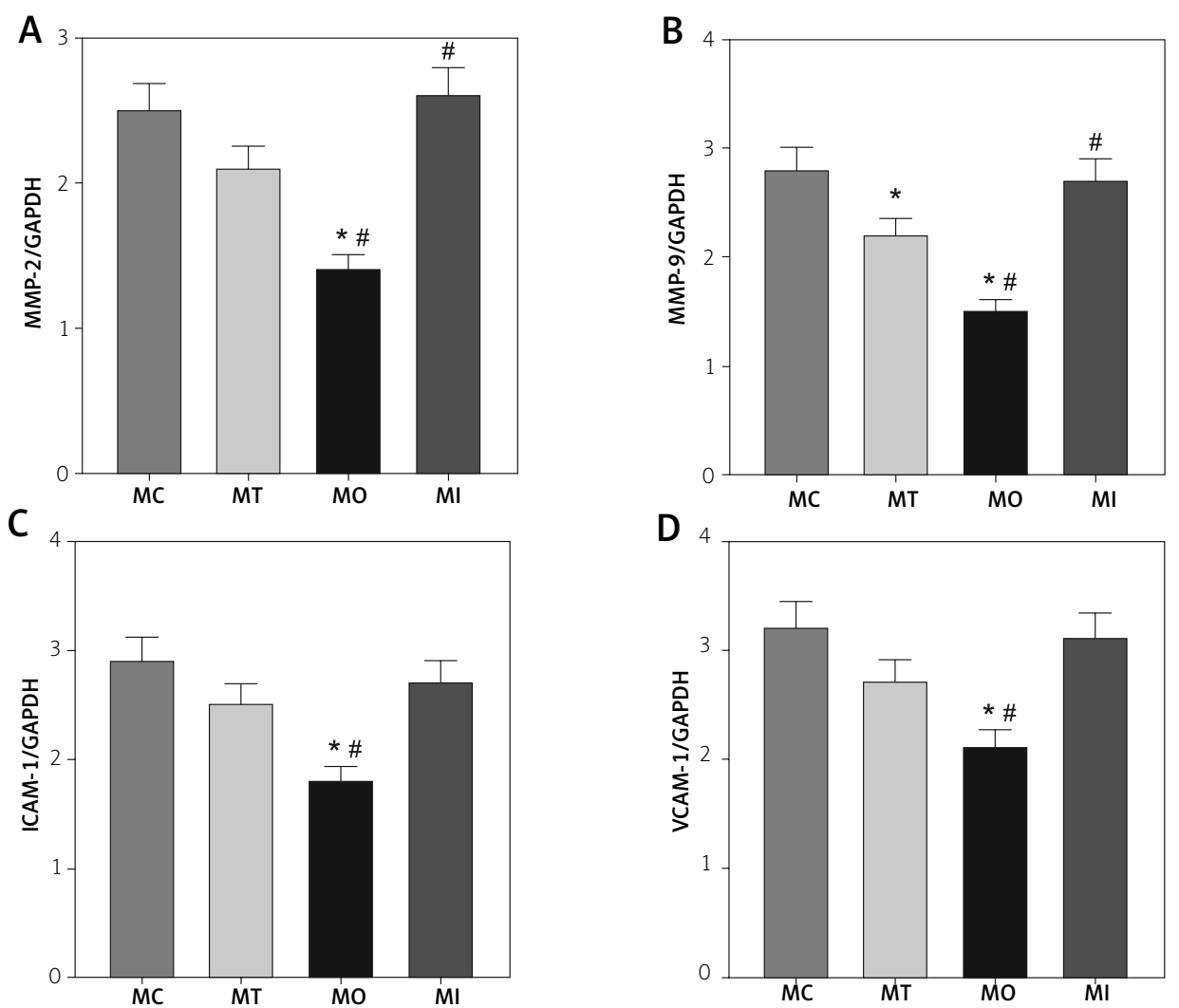

Fig. 3. Detection of metastasis-related genes expression using qPCR method in each group of U-138MG cell model under treatment of vemurafenib. A) Expression of MMP-2 in each group of cell model under treatment of vemurafenib. B) Expression of MMP-9 in each group of cell model under treatment of vemurafenib. C) Expression of ICAM-1 in each group of cell model under treatment of vemurafenib. D) Expression of VCAM-1 in each group of cell model under treatment of vemurafenib. Data presented as mean \pm SD. Each experiment was repeated 3 times independently. ${ }^{*} p<0.05$ compared with control group, ${ }^{*} p<0.05$ compared with vemurafenib treatment group.

in each group of the U-87MG cell model was 132.1 $\pm 7.8,112.6 \pm 6.6,85.4 \pm 5.0$, and $129.6 \pm 7.6 \mathrm{pg} / \mathrm{ml}$, respectively, and the concentration was 362.1 $\pm 21.3,300.8 \pm 17.7,231.6 \pm 13.6$, and $348.7 \pm 20.5$ $\mathrm{pg} / \mathrm{ml}$, respectively, in each group of the U-138MG cell model. The concentration of VCAM-1 in each group of the U-87MG cell model was $230.6 \pm 13.6$, $204.2 \pm 12.0,145.3 \pm 8.5$, and $229.1 \pm 13.5 \mathrm{pg} / \mathrm{ml}$, respectively, and the concentration was $485.1 \pm 28.5$, $432 \pm 25.4,348.5 \pm 20.5$, and $475.3 \pm 28.0 \mathrm{pg} / \mathrm{ml}$, respectively, in each group of the $U-138 M G$ cell model.

\section{Expression of metastasis-related proteins in cell models}

As shown in Figures 6 and 7, the expression of E-cadherin in the NC, VT, VO, and VI groups of the $\mathrm{U}-87 \mathrm{MG}$ cell model was $0.79 \pm 0.05,1.25 \pm 0.07,1.47$ \pm 0.09 , and $1.03 \pm 0.06$, respectively, and the expression of E-cadherin in the MC, MT, MO, and MI groups of the $U-138 M G$ cell model was $0.54 \pm 0.03,0.62 \pm 0.04$, $0.74 \pm 0.04$, and $0.06 \pm 0.01$, respectively. The expression of MMP-2 in each group of the U-87MG cell model was $0.97 \pm 0.06,0.96 \pm 0.06,0.82 \pm 0.05$, and $1.35 \pm 0.08$, respectively, and the expression was $1.02 \pm 0.06,0.76 \pm 0.04,0.42 \pm 0.02$, and $1.00 \pm 0.06$, respectively, in each group of the $\mathrm{U}-138 \mathrm{MG}$ cell model. The expression of MMP-9 in each group of the U-87MG cell model was $1.13 \pm 0.07,0.74 \pm 0.04$, $0.21 \pm 0.01$, and $0.97 \pm 0.06$, respectively, and the expression was $1.12 \pm 0.07,1.05 \pm 0.06,0.55 \pm 0.03$, and $0.89 \pm 0.05$, respectively, in each group of the $\mathrm{U}-138 \mathrm{MG}$ cell model. The expression of LAMP-1 in each group of the $U-87 M G$ cell model was $1.10 \pm 0.06$, $1.10 \pm 0.06,0.72 \pm 0.04$, and $1.66 \pm 0.10$, respectively, 

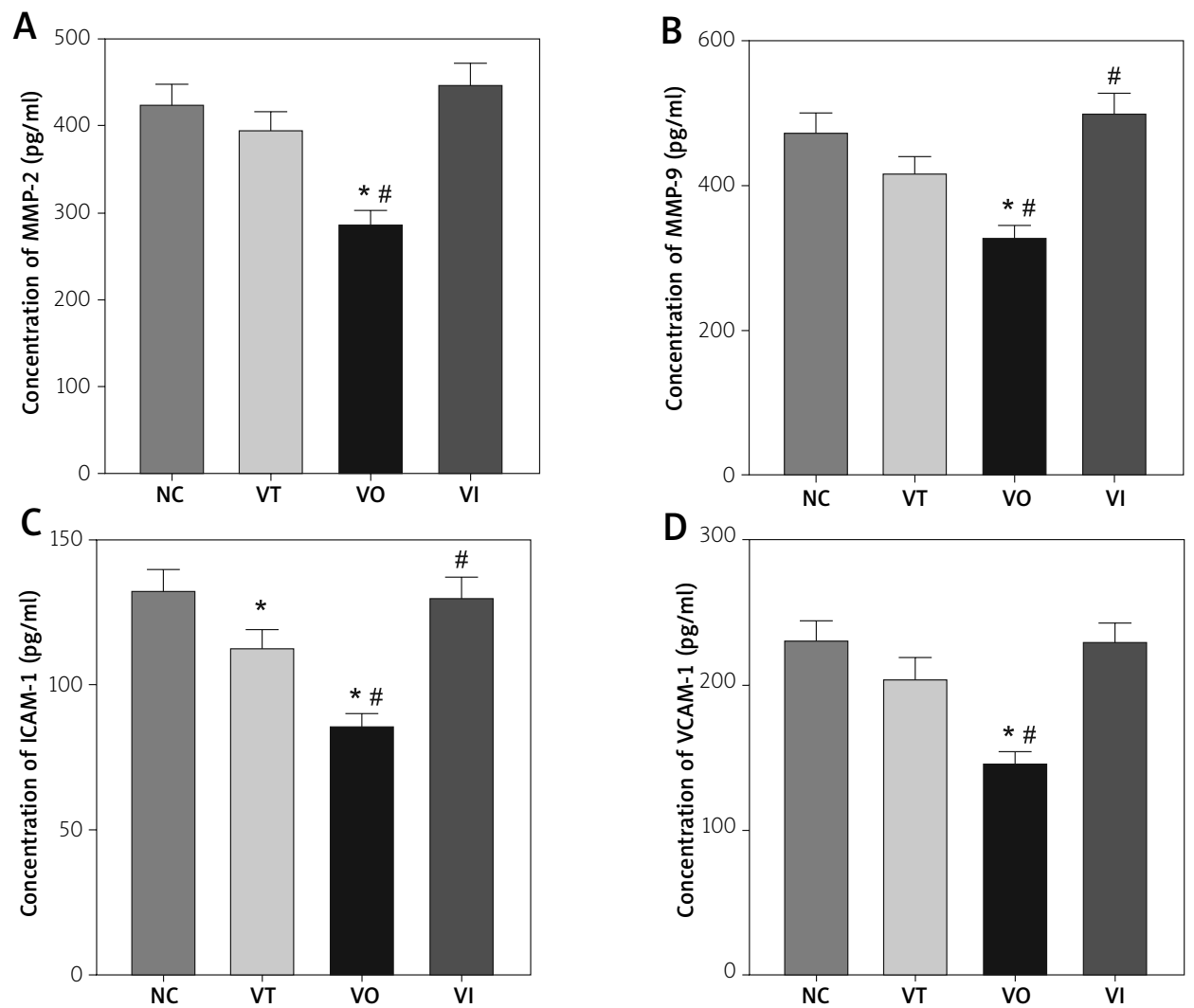

Fig. 4. Detection of concentration of metastasis-related factors using ELISA method in each group of cultured mediums of U-87MG cell model under treatment of vemurafenib. A) Concentration of MMP-2 in cultured medium of each group of cell model under treatment of vemurafenib. B) Concentration of MMP-9 in cultured medium of each group of cell model under treatment of vemurafenib. C) Concentration of ICAM-1 in cultured medium of each group of cell model under treatment of vemurafenib. D) Concentration of VCAM-1 in cultured medium of each group of cell model under treatment of vemurafenib. Data presented as mean \pm SD. Each experiment was repeated 3 times independently. ${ }^{*} p<0.05$ compared with control group, ${ }^{*} p<0.05$ compared with vemurafenib treatment group.

and the expression was $0.82 \pm 0.05,0.70 \pm 0.04,0.32$ \pm 0.02 , and $0.82 \pm 0.05$, respectively, in each group of the U-138MG cell model. The expression of LAMP-2 in each group of the U-87MG cell model was 1.21 $\pm 0.07,1.08 \pm 0.06,0.80 \pm 0.05$, and $1.64 \pm 0.10$, respectively, and it was $1.61 \pm 0.09,1.53 \pm 0.09,1.14$ \pm 0.07 , and $1.89 \pm 0.11$, respectively, in each group of U-138MG cells.

\section{Activation of JAK2/STAT3 signalling pathway in cell models}

As shown in Figures 8 and 9, the ratio of p-STAT3/ STAT3 in NC, VT, VO, and VI groups of the U-87MG cell model was $0.26 \pm 0.02,0.19 \pm 0.01,0.17 \pm 0.01$, and $0.23 \pm 0.01$, respectively, and the ratio was $0.30 \pm 0.02$, $0.31 \pm 0.02,0.12 \pm 0.01$, and $0.24 \pm 0.01$, respectively, in the MC, MT, MO, and MI groups of the U-138MG model. The ratio of $\mathrm{p}-J A K 2 / J A K 2$ in each group of the $\mathrm{U}-87 \mathrm{MG}$ cell model was $0.21 \pm 0.01,0.17 \pm 0.01,0.12$ \pm 0.01 , and $0.20 \pm 0.01$, respectively, and the ratio was $0.23 \pm 0.01,0.22 \pm 0.01,0.10 \pm 0.01$, and 0.19 \pm 0.01 , respectively, in each group of the $U-138 \mathrm{MG}$ cell model. The expression of SNX10 in each group of the $U-87 M G$ cell model was $0.31 \pm 0.02,0.60 \pm 0.04$, $0.96 \pm 0.06$, and $0.40 \pm 0.02$, respectively, and the expression was $0.11 \pm 0.01,0.38 \pm 0.02,0.53 \pm 0.03$, and $0.03 \pm 0.01$, respectively, in each group of the $\mathrm{U}-138 \mathrm{MG}$ cell model. The expression of BAX in each group of the U-87MG cell model was $0.45 \pm 0.03$, $0.80 \pm 0.05,0.96 \pm 0.06$, and $0.55 \pm 0.03$, respectively, and the expression was $0.52 \pm 0.03,1.15 \pm 0.07,1.32$ \pm 0.08 , and $0.81 \pm 0.05$, respectively, in each group of the U-138MG cell model. The expression of $p-53$ in each group of the $U-87 M G$ cell model was $0.36 \pm 0.02$, 

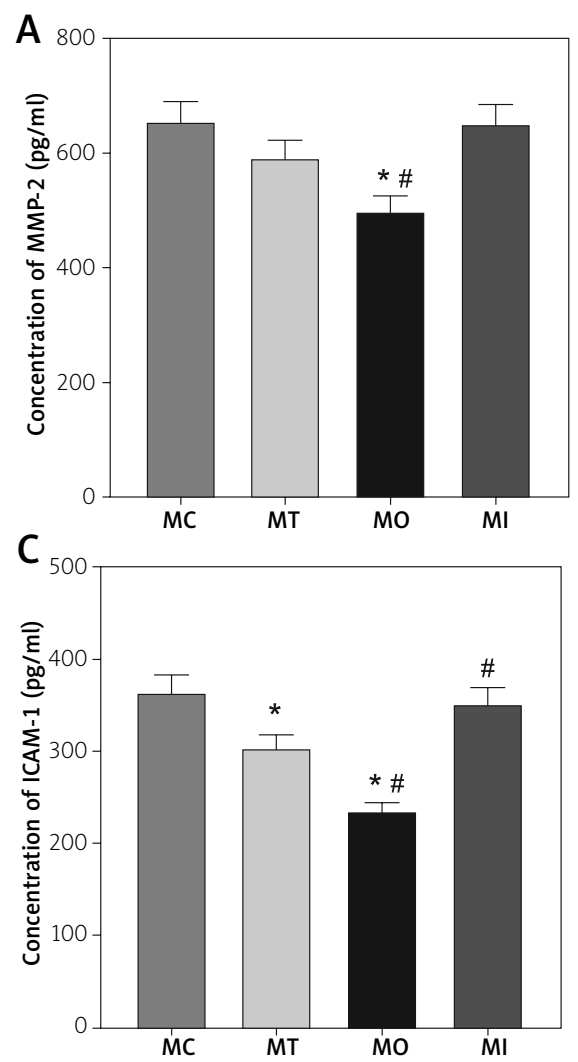
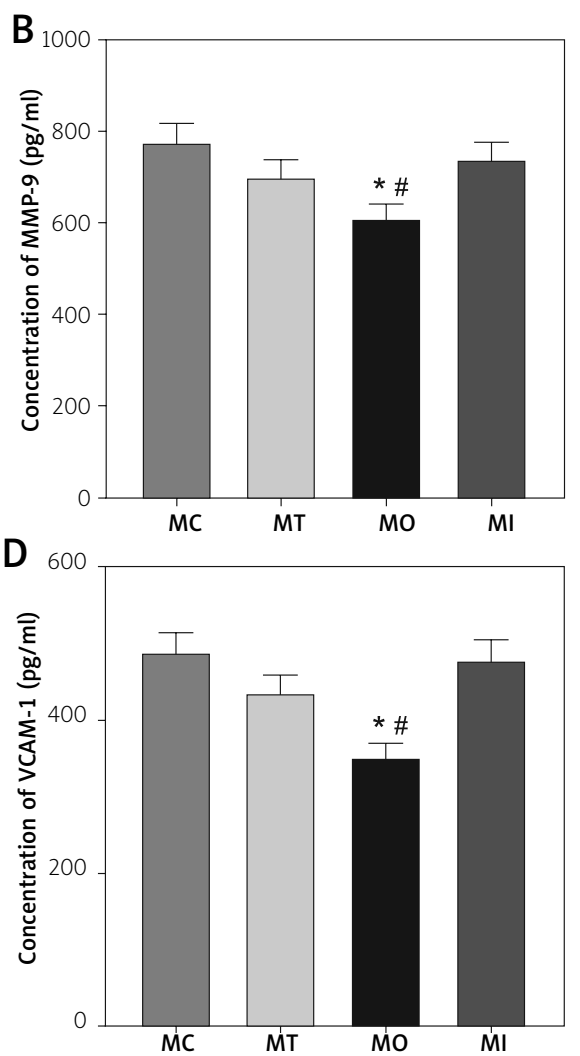

Fig. 5. Detection of concentration of metastasis-related factors using ELISA method in each group of cultured mediums of U-138MG cell model under treatment of vemurafenib. A) Concentration of MMP-2 in cultured medium of each group of cell model under treatment of vemurafenib. B) Concentration of MMP-9 in cultured medium of each group of cell model under treatment of vemurafenib. C) Concentration of ICAM-1 in cultured medium of each group of cell model under treatment of vemurafenib. D) Concentration of VCAM-1 in cultured medium of each group of cell model under treatment of vemurafenib. Data presented as mean \pm SD. Each experiment was repeated 3 times independently. ${ }^{*} p<0.05$ compared with control group, ${ }^{\#} p<0.05$ compared with vemurafenib treatment group.

$0.76 \pm 0.04,0.90 \pm 0.05$, and $0.48 \pm 0.03$, respectively, and the expression was $0.56 \pm 0.03,1.10 \pm 0.06,1.28$ \pm 0.08 , and $0.85 \pm 0.05$, respectively, in each group of the U-138MG cell model. The expression of SOX11 in each group of the $\mathrm{U}-87 \mathrm{MG}$ cell model was 0.15 $\pm 0.01,0.59 \pm 0.03,0.92 \pm 0.05$, and $0.47 \pm 0.03$, respectively, and the expression was $0.30 \pm 0.02,0.61$ $\pm 0.04,0.74 \pm 0.04$, and $0.18 \pm 0.01$, respectively, in each group of the $\mathrm{U}-138 \mathrm{MG}$ cell model.

\section{Discussion}

Glioma is one of the most frequent tumours in adults. The proportion of glioma in intracranial tumours is $40.49 \%$ according to a previous study [20], and the average survival period of glioma patients after diagnosis is less than 5 years [2]; thus, glioma is a malignant disease with high mortality and disability. A small molecule inhibitor of BRAFV600E, vemurafenib has been successfully used in the treatment of metastatic melanoma patients [16]; however, few studies focus on the effect of vemurafenib on the treatment of glioma.

Metastasis is the final step of tumour formation and leads to the morbidity and mortality of cancer patients, in which the spread of cancer cells from the primary tumour to nearby tissues plays an important role [34]. The underlying mechanism of cancer metastasis is called epithelial-mesenchymal transition (EMT), which includes destruction of intercellular relationships, extracellular matrix (ECM) breakdown, and regulation of cleavage of basement membrane by matrix metalloproteinase (MMP) 

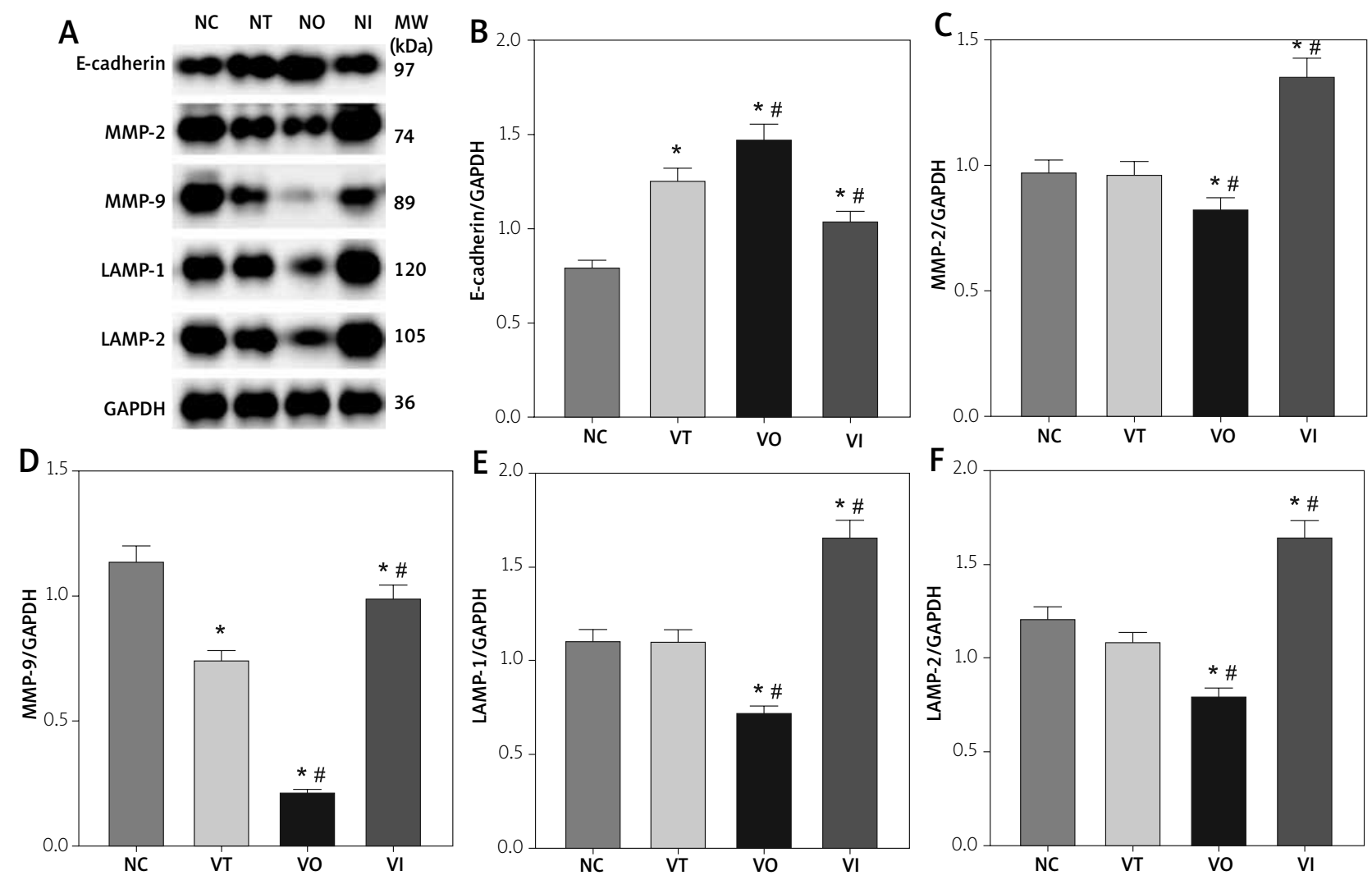

Fig. 6. Detection of metastasis-related proteins in each group of U-87MG cell model under treatment of vemurafenib. A) Expression of E-cadherin, MMP-2, MMP-9, LAMP-1, and LAMP-2 in each group of cell model under treatment of vemurafenib. B-F) Quantitative analysis of each target protein. Data presented as mean \pm SD. Each experiment was repeated 3 times independently. ${ }^{*} p<0.05$ compared with control group, ${ }^{\#} p<0.05$ compared with vemurafenib treatment group.

activity [24]. A previous study found that MMPs are critical factors in the promotion of angiogenesis and metastasis processes via regulation of EMT [12]. MMPs contains a family of metalloproteinases with a zinc-binding domain, and present a critical function in degradation of ECM components. They were proven to be involved in the regulation of cancer metastasis over 50 years ago [8], and recently a study indicated that MMPs also play a critical role in the regulation of angiogenesis [12], resulting in migration of tumour cells into nearby tissues. MMP-2 and MMP-9 are the subtypes of the MMPs family, which can degrade type IV collagen and are highly expressed in human cancer. Using an in vivo experiment, researchers found that MMP-2 and MMP-9 presents a cooperative effect in promoting the invasiveness of tumour keratinocytes [18]. Another study also found that MMP-2 and MMP-9 lead to the angiogenesis of cancer via activation of transforming growth factor $\beta$ (TGF- $\beta$ ) via a CD44-dependent manner, resulting in the promotion of tumour growth and invasion [37]. LAMP-1 and LAMP-2 are major constituents of lysosomal membrane and are classified as type I transmembrane proteins [33]. A previous study showed that knockout of LAMP-1 and LAMP-2 in mice developed into embryonic lethality, indicating that these 2 proteins play an important role in maintaining cellular homeostasis [9]. More and more research has shown that LAMP-1 and LAMP-2 play a pro-invasion and pro-metastasis role in progression of cancer, and elevated expression of LAMP-1 has been found in breast cancer cells associated with the migration of cancer cells [28]. Besides, LAMP-1 and LAMP-2 expression also binds with E-selectin and galectin-3 through poly-N-acetyllactosamine (polyLacNAc), and further activates ERK 

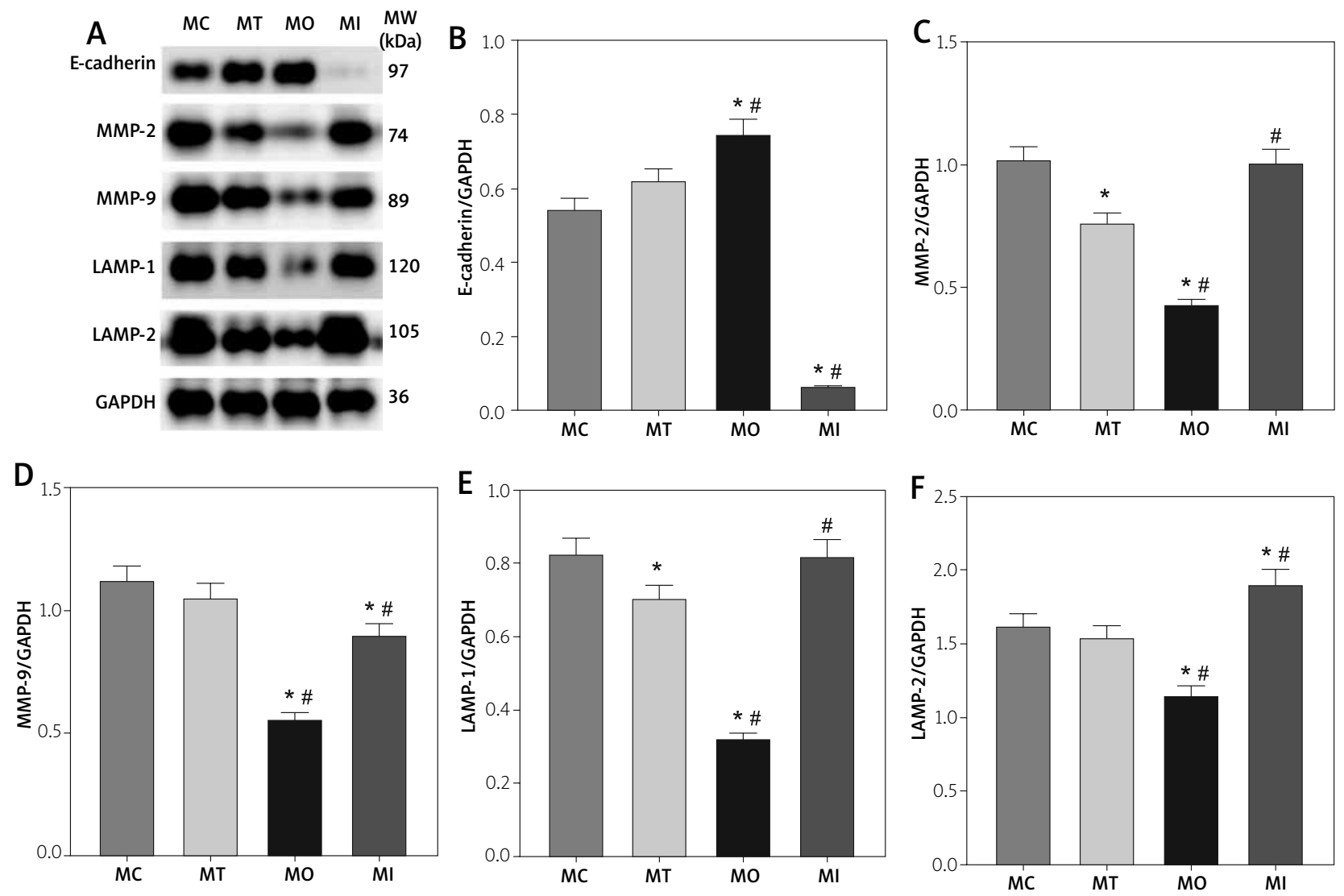

Fig. 7. Detection of metastasis related proteins in each group of U-138MG cell model under treatment of vemurafenib. A) Expression of E-cadherin, MMP-2, MMP-9, LAMP-1, and LAMP-2 in each group of cell model under treatment of vemurafenib. B-F) Quantitative analysis of each target protein. Data presented as mean \pm SD. Each experiment was repeated 3 times independently. ${ }^{*} p<0.05$ compared with control group, ${ }^{*} p<0.05$ compared with vemurafenib treatment group.

and p38 signalling pathways, leading to the expression of MMPs and degradation of ECM [6]. Here, we found that the expression of pro-metastasis and pro-invasion was decreased in vemurafenib combined with USP38 overexpression in the treatment group, indicating that overexpression of USP38 presented an anti-tumour effect, while the detailed mechanism was not clear.

Sex-determining region Y-related HMG-box 11 (SOX11) is a type of structurally related transcription factor and belongs to group C of the SOX family. Expression of transcription factors is strictly regulated by binding with DNA domains; under this mechanism, SOXs regulate differentiation, organogenesis, and other cellular process. A recent study discovered that overexpression of SOX11 would suppress the migration and invasion of prostate cancer cells [26], and activation of SOX11 promoter was significantly higher in cancer cells compared with normal group [32]. A previous study noted that STAT3 is one of the downstream targets of SOX11 via activation of JAK signalling pathway [21]. Janus kinase (JAK)/signal transducer and activator of transcription (STAT) pathway play a critical role in regulation of tumour development and survival. Among family members of the JAK and STAT family, JAK2/STAT3 is the most studied signalling pathway in the pathogenesis of cancer via induction of EMT [36]. It was previously shown that activation of JAK2/STAT3 increases the metastasis ability of cancer cells via up-regulation of EMT-inducing transcription factors [14]. JAK2/STAT3 also activates in a gastrin-dependent manner and further inhibits the cellular adhesion process via inhibition of MMP secretion and the expression of E-cadherin [10]. In the present study, we found that overexpression of USP38 enhanced the effect of vemurafenib on inhibi- 

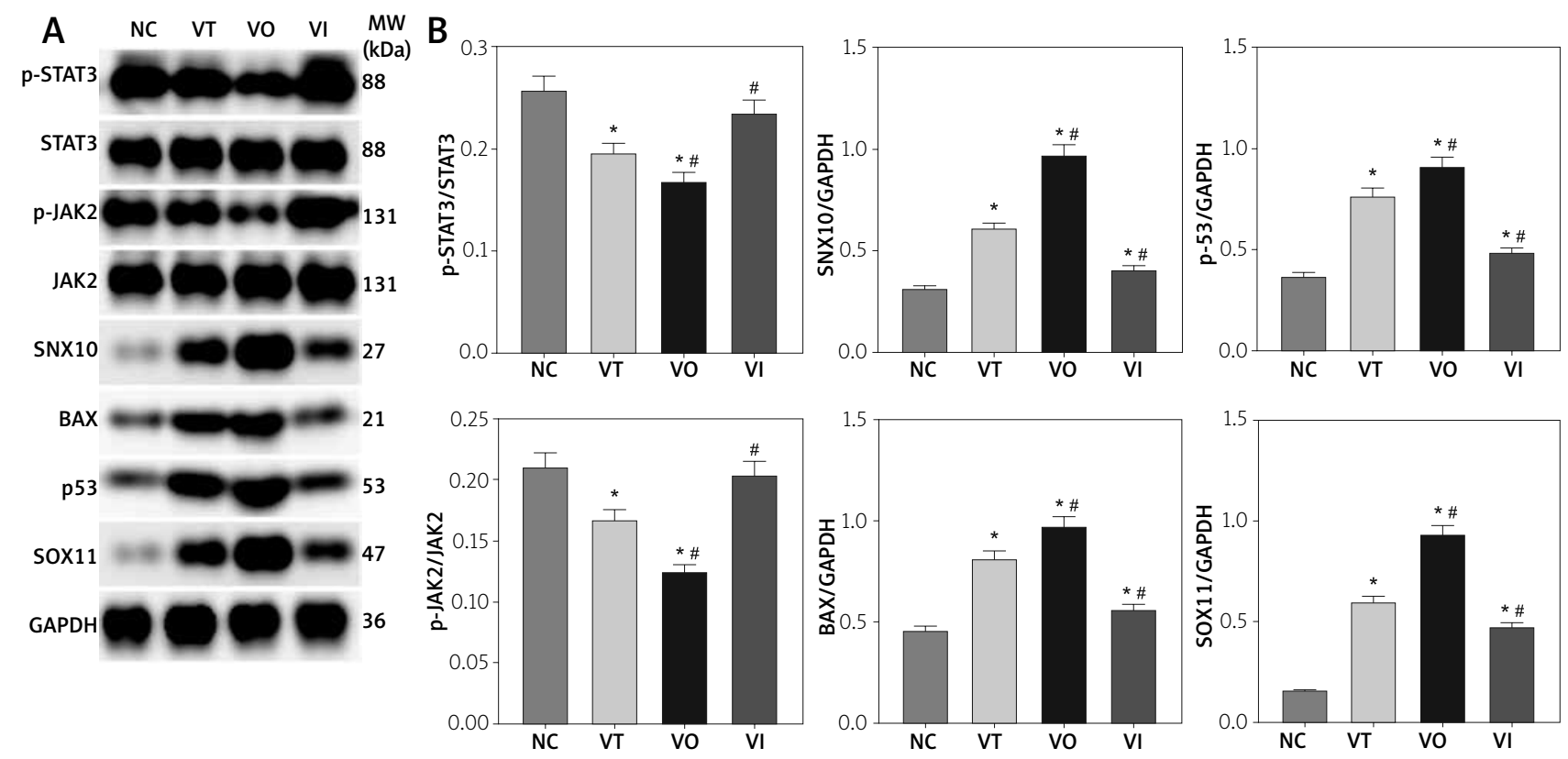

Fig. 8. Detection of JAK2/STAT3 signalling pathway in each group of U-87MG cell model under treatment of vemurafenib. A) Expression of p-JAK2, JAK2, p-STAT3, STAT3, SNX10, BAX, p53, and SOX11 in each group of cell model under treatment of vemurafenib. B) Quantitative analysis of each target protein. Data presented as mean \pm SD. Each experiment was repeated 3 times independently. ${ }^{*} p<0.05$ compared with control group, ${ }^{\#} p<0.05$ compared with vemurafenib treatment group.
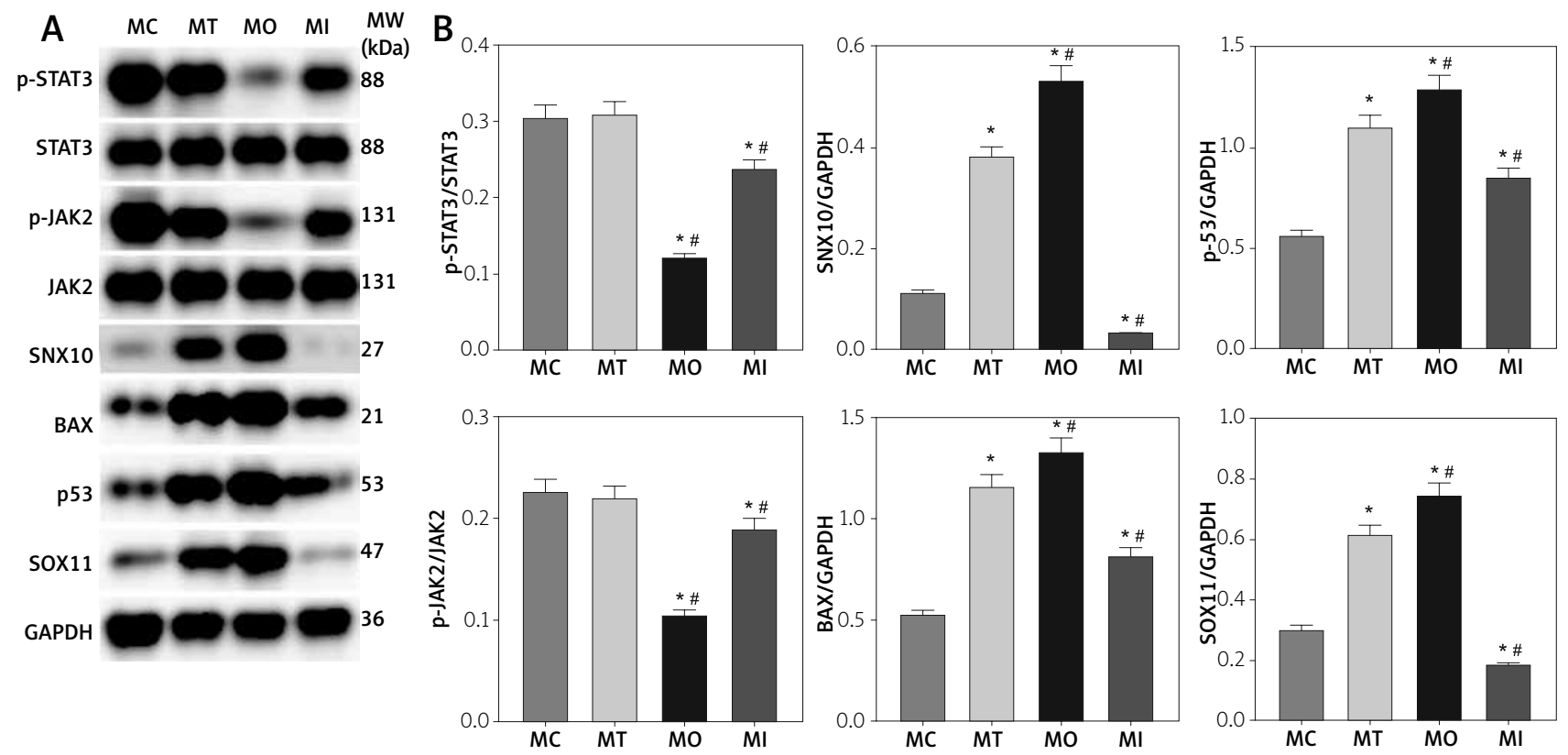

Fig. 9. Detection of JAK2/STAT3 signalling pathway in each group of U-138MG cell model under treatment of vemurafenib. A) Expression of p-JAK2, JAK2, p-STAT3, STAT3, SNX10, BAX, p53 and SOX11 in each group of cell model under treatment of vemurafenib. B) Quantitative analysis of each target protein. Data presented as mean \pm SD. Each experiment was repeated 3 times independently. ${ }^{*} p<0.05$ compared with control group, ${ }^{\#} p<0.05$ compared with vemurafenib treatment group. 
tion of JAK/STAT3 signalling pathway activation, and that might be the mechanism of inhibition of pro-metastasis and pro-invasion molecule expression, leading to the anti-tumour effect.

P53 could induce the expression of many genes involved in multiple signalling pathways related to cellular apoptosis [25]. BAX is a member of the $\mathrm{BH} 3$ domain-only pro-apoptotic proteins; activation of p-53 further activates the $\mathrm{BH} 3$-only proteins, leading to the permeabilization of the mitochondrial outer membrane [29]. Sorting nexin 10 (SNX10) is a member of the sorting nexins (SNXs) family, which contains the phox homology domain, targeting SNXs to endosome membrane via binding with phosphoinositide to regulate endosomal transport [5]. Recently a study found that SNX10 plays a critical role in alcohol-induced liver injury and steatosis via regulation the degradation of LAMP2 [35], and thus has been regarded as a tumour suppressor protein in CRC [38]. In this study, we found that overexpression of USP38 enhanced the inhibition effect of vemurafenib on expression of SNX10, presenting an anti-tumour effect.

Here, we noticed that vemurafenib treatment elevated the expression of BAX and p53, inducing the reduction of cellular proliferation rate. Also, vemurafenib treatment reduced the expression of MMPs and LAMPS, resulting in a reduction of the degradation of ECM and metastasis ability of cancer cells. And we also noticed that these effects were increased by overexpression of USP38, and these effects might be mediated by reduction of activation of JAK2/STAT3 signalling pathway. Thus, USP38 might be a therapeutic target in the treatment of glioma.

\section{Disclosure}

The authors report no conflict of interest.

\section{References}

1. Bollag G, Hirth P, Tsai J, Zhang JZ, Ibrahim PN, Cho H, Spevak W, Zhang C, Zhang Y, Habets G, Burton EA, Wong B, Tsang G, West BL, Powell B, Shellooe R, Marimuthu A, Nguyen $H$, Zhang KYJ, Artis DR, Schlessinger J, Su F, Higgins B, lyer R, D’Andrea K, Koehler A, Stumm M, Lin PS, Lee RJ, Grippo J, Puzanov I, Kim KB, Ribas A, McArthur GA, Sosman JA, Chapman PB, Flaherty KT, XU XW, Nathanson KL, Nolop K. Clinical efficacy of a RAF inhibitor needs broad target blockade in BRAF mutant melanoma. Nature 2010; 467: 596-599.
2. Chen R, Smith-Cohn M, Cohen AL, Colman H. Glioma subclassifications and their clinical significance. Neurotherapeutics 2017; 14: 284-297.

3. Clague MJ, Barsukov I, Coulson JM, Liu H, Rigden DJ, Urbé S. Deubiquitylases from genes to organism. Physiol Rev 2013; 93 : 1289-1315.

4. Clague MJ, Urbe S, Komander D. Breaking the chains: deubiquitylating enzyme specificity begets function. Nat Rev Mol Cell Biol 2019; 20: 338-352.

5. Cullen PJ, Korswagen HC. Sorting nexins provide diversity for retromer dependent trafficking events. Nat Cell Biol 2011; 14: 29-37.

6. Dange MC, Agarwal AK, Kalraiya RD. Extracellular galectin-3 induces MMP9 expression by activating p38 MAPK pathway via lysosome-associated membrane protein-1 (LAMP1). Mol Cell Biol 2015; 404: 79-86.

7. Difilippantonio MJ, Zhu J, Chen HT, Meffre E, Nussenzweig MC, Max EE, Ried T, Nussenzweig A. DNA repair protein Ku80 suppresses chromosomal aberrations and malignant transformation. Nature 2000; 404: 510-514.

8. Ehrmann RL, Knoth M. Choriocarcinoma: transfilter stimulation of vasoproliferation in the hamster cheek pouch. Studied by light and electron microscopy. J Natl Cancer Inst 1968; 41: 1329-1341.

9. Eskelinen EL. Roles of LAMP-1 and LAMP-2 in lysosome biogenesis and autophagy. Mol Aspects Med 2006; 27: 495-502.

10. Ferrand A, Kowalski-Chauvel A, Bertrand C, Pradayrol L, Fourmy D, Dufresne M, Seva C. Involvement of JAK2 upstream of the PI 3-kinase in cell-cell adhesion regulation by gastrin. Exp Cell Res 2004; 301: 128-138.

11. Frank KM, Sharpless NE, Gao Y, Sekiguchi JM, Ferguson DO, Zhu C, Manis JP, Horner J, DePinho RA, Alt FW. DNA ligase IV deficiency in mice leads to defective neurogenesis and embryonic lethality via the p53 pathway. Mol Cell 2000; 5: 993-1002.

12. Fukushima R, Kasamatsu A, Nakashima D, Higo M, Fushimi K, Kasama H, Endo-Sakamoto Y, Shiiba M, Tanzawa H, Uzawa K. Overexpression of translocation associated membrane protein 2 leading to cancer-associated matrix metalloproteinase activation as a putative metastatic factor for human oral cancer. J Cancer 2018; 9: 3326-3333.

13. Gao Y, Ferguson DO, Xie W, Manis JP, Sekiguchi J, Frank KM, Chaudhuri J, Horner J, DePinho RA, Alt FW. Interplay of p53 and DNA-repair protein XRCC4 in tumorigenesis, genomic stability and development. Nature 2000; 404: 897-900.

14. Gong C, Shen J, Fang Z, Qiao L, Feng RF, Lin XM, Li SY. Abnormally expressed JunB transactivated by IL-6/STAT3 signaling promotes uveal melanoma aggressiveness via epithelial-mesenchymal transition. Biosci Rep 2018; 38: BSR20180532.

15. Komander D, Clague MJ, Urbe S. Breaking the chains: structure and function of the deubiquitinases. Nat Rev Mol Cell Biol 2009; 10: 550-563.

16. Kopetz S, Desai J, Chan E, Hecht JR, O’Dwyer PJ, Maru D, Morris V, Janku F, Dasari A, Chung W, Issa JPJ, Gibbs P, James B, Powis G, Nolop KB, Bhattacharya S, Saltz L. Phase II pilot study of vemurafenib in patients with metastatic BRAF-mutated colorectal cancer. J Clin Oncol 2015; 33: 4032-4038. 
17. Livak KJ, Schmittgen TD. Analysis of relative gene expression data using real-time quantitative PCR and the 2(-Delta Delta $C(T)$ ) method. Methods 2001; 25: 402-408.

18. Masson V, de la Ballina LR, Munaut C, Wielockx B, Jost M, Maillard C, Blacher S, Bajou K, Itoh T, Itohara S, Werb Z, Libert C, Foidart JM, Noël A. Contribution of host MMP-2 and MMP-9 to promote tumor vascularization and invasion of malignant keratinocytes. FASEB J 2005; 19: 234-236.

19. Mevissen TET, Komander D. Mechanisms of deubiquitinase specificity and regulation. Annu Rev Biochem 2017; 86: 159-192.

20. Molinaro AM, Taylor JW, Wiencke JK, Wrensch MR. Genetic and molecular epidemiology of adult diffuse glioma. Nat Rev Neurol 2019; 15: 405-417.

21. Mohanty A, Sandoval N, Phan A, Nguyen TV, Chen RW, Budde E, Mei M, Popplewell L, Pham LV, Kwak LW, Weisenburger DD, Rosen ST, Chan WC, Müschen M, Ngo VN. Regulation of SOX11 expression through CCND1 and STAT3 in mantle cell lymphoma. Blood 2019; 133: 306-318.

22. Pogoda K, Bucki R, Byfield FJ, Cruz K, Lee T, Marcinkiewicz C, Janmey PA. Soft substrates containing hyaluronan mimic the effects of increased stiffness on morphology, motility, and proliferation of glioma cells. Biomacromolecules 2017; 18: 30403051.

23. Prete A, Lo AS, Sadow PM, Bhasin SS, Antonello ZA, Vodopivec SM, Ullas S, Sims JN, Clohessy J, Dvorak AM, Sciuto T, Bhasin M, Murphy-Ullrich JE, Lawler J, Karumanchi SA, Carmelo Nucera. Pericytes elicit resistance to vemurafenib and sorafenib therapy in thyroid carcinoma via the TSP-1/TGF 1 axis. Clin Cancer Res 2018; 24: 6078-6097.

24. Pugongchai A, Bychkov A, Sampatanukul P. Promoter hypermethylation of SOX11 correlates with adverse clinicopatholog. ical features of human prostate cancer. Int J Exp Pathol 2017; 98: 341-346.

25. Riley T, Sontag E, Chen P, Levine A. Transcriptional control of human p53-regulated genes. Nat Rev Mol Cell Biol 2008; 9: 402-412.

26. Seyfried TN, Huysentruyt LC. On the origin of cancer metastasis. Crit Rev Oncog 2013; 18: 43-73.

27. Singh BP, Salama AK. Updates in therapy for advanced melanoma. Cancers 2016; 8: 1

28. Tan KP, Ho MY, Cho HC, Yu J, Hung JT, Yu ALT. Fucosylation of LAMP-1 and LAMP-2 by FUT1 correlates with lysosomal positioning and autophagic flux of breast cancer cells. Cell Death Dis 2016; 7: e2347.

29. Tait SW, Green DR. Mitochondria and cell death: Outer membrane permeabilization and beyond. Nat Rev Mol Cell Biol 2010; 11: 621-632.

30. Thompson EW, Williams ED. EMT and MET in carcinoma - clinical observations, regulatory pathways and new models. Clin Exp Metastasis 2008; 25: 591-592.

31. Tsidulko AY, Kazanskaya GM, Volkov AM, Suhovskih AV, Kiselev RS, Kobozev VV, Gaytan AS, Krivoshapkin AL, Aidagulova SV, Grigorieva EV. Chondroitin sulfate content and decorin expression in glioblastoma are associated with proliferative activity of glioma cells and disease prognosis. Cell Tissue Res 2020; 379: 147-155.
32. Valastyan S, Weinberg RA. Tumor metastasis: molecular insights and evolving paradigms. Cell 2011; 147: 275-292.

33. Wilke S, Krausze J, Bussow K. Crystal structure of the conserved domain of the DC lysosomal associated membrane protein: implications for the lysosomal glycocalyx. BMC Biol 2012; 10: 62.

34. Yao Z, Sun B, Hong Q, Yan JM, Mu D, Li JY, Sheng HB, Guo HQ. The role of tumor suppressor gene SOX11 in prostate cancer. Tumour Biol 2015; 36: 6133-6138.

35. You Y, Li WZ, Zhang S, Hu B, Li YX, Li HD, Tang HH, Li QW, Guan YY, Liu LX, Bao WL, Shen X. SNX10 mediates alcohol-induced liver injury and steatosis by regulating the activation of chaperone-mediated autophagy. J Hepatol 2018; 69: 129-141.

36. Yu H, Pardoll D, Jove R. STATs in cancer inflammation and immunity: A leading role for STAT3. Nat Rev Cancer 2009; 9: 798-809.

37. Yu Q, Stamenkovic I. Cell surface-localized matrix metalloproteinase9 proteolytically activates TGF- $\beta$ and promotes tumor invasion and angiogenesis. Genes Dev 2000; 14: 163-176.

38. Zhang S, Hu B, You Y, Yang Z, Liu L, Tang H, Bao W, Guan Y, Shen $X$. Sorting nexin 10 acts as a tumor suppressor in tumorigenesis and progression of colorectal cancer through regulating chaperone mediated autophagy degradation of p21(Cip1/ WAF1). Cancer Lett 2018; 419: 116-127.

39. Zhu S, Li W, Liu J, Chen CH, Liao Q, Xu P, Xu H, Xiao T, Cao Z, Peng J, Yuan P, Brown M, Liu XS, Wei W. Genome-scale deletion screening of human long non-coding RNAs using a paired-guide RNA CRISPR-Cas9 library. Nat Biotechnol 2016; 34: 1279-1286. 